\title{
Mulemba
}

Revista Angolana de Ciências Sociais

6 (12) | 2016

Sobre a sociedade e a cultura em Angola e alhures:

algumas reflexões de percepções sobre a realidade e múltiplas experiências

\section{Acerca das contradições de Carlos Serrano na obra Os Senhores da Terra e os Homens do Mar}

\section{Bortolami Gabriele}

\section{OpenEdition \\ Journals}

\section{Edição electrónica}

URL: http://journals.openedition.org/mulemba/1197

DOI: $10.4000 /$ mulemba. 1197

ISSN: 2520-0305

\section{Editora}

Edições Pedago

Edição impressa

Data de publição: 1 novembro 2016

Paginação: 331-336

ISSN: 2182-6471

Refêrencia eletrónica

Bortolami Gabriele, «Acerca das contradições de Carlos Serrano na obra Os Senhores da Terra e os Homens do Mar», Mulemba [Online], 6 (12) | 2016, posto online no dia 13 outubro 2018, consultado o 26 janeiro 2021. URL: http://journals.openedition.org/mulemba/1197 ; DOI: https://doi.org/10.4000/ mulemba. 1197 


\section{Acerca das contradições de Carlos Serrano na obra Os Senhores da Terra e os Homens do Mar*}

\section{Bortolami Gabriele ${ }^{* *}$}

A leitura da obra La vie quotidienne au royaume de Kongo du хиге au хиıIе siècle (1965) de Georges Balandier, fez nascer o interesse e o projecto de repetir com a mesma óptica a análise da cultura cabinda operada por Carlos Serrano no seu precioso livro Os Senhores da Terra e os Homens do Mar. Uma operação de facto interessante, porém, que não deixa de ser uma construção. O pressuposto que anima Balandier na análise dos Bakongo pode ser definido como "presente etnográfico», ou seja, fixam-se no presente dados culturais relevados pela análise etnográfica que, mais tarde, são expostos e narrados, como se não houvesse um passado donde provinham e um futuro, que mais tarde os modificou. Enfim um acontecimento, um costume, um hábito são como que fotografados e como tal permanecem como determinados papéis ou como quadros de uma qualquer exposição. Ora isso está em franca contradição com a perspectiva dinâmica que, como sabemos, anima toda a obra de Georges Balandier, tal como esta tem sido definida como uma antropologia dinâmica ou dinamista.

* Texto da apresentação pública da obra do antropólogo Carlos Serrano, Os Senhores da Terra e os Homens do Mar (Luanda, Kilombelombe 2015, [ «Ciências Humanas e Sociais: Série Sociologia e Antropologia»; 9]), apresentada no anfiteatro principal da Faculdade de Ciências Sociais (FCS) da Universidade Agostinho Neto (UAN), em Luanda, no dia 11 de Agosto de 2016.

** Professor Auxiliar do Departamento de Antropologia (DA) da Faculdade de Ciências Sociais (FCS) da Universidade Agostinho Neto (UAN). 
Justamente, vendo as coisas como tem sido costume observar-se, constatamos que quando uma pesquisa é séria, é dever de qualquer autor começa por indagar as suas fontes; porém, nesta sua obra, Serrano inicia essa indagação por Michel Duchet ou Theóphile Obenga (SERRANo 2014: 30), isto é, dois historiadores modernos colocados como referentes principais, sem antes ter examinado as fontes antigas sobre o Kongo, por exemplo, com o italiano Filippo Pigafetta. De qualquer forma, esse facto não tira nada à profundidade deste estudo. Basta ver a maneira como Serrano aborda Andrew Battel, um refém inglês que os Portugueses enviam para Angola, e que mais tarde para sair da cadeia é obrigado a enquadrar-se na tropa «colonial». As suas preciosas observações da Angola desse tempo foram registadas e constituem hoje uma fonte preciosa sobre essa época. Nesta conformidade, entendemos que para uma pesquisa ter um corte antropológico, seria necessário antes colocar autores que possam enquadrar metodologicamente a própria investigação. De facto, se fossémos ver a crítica que move Radcliffe-Brown ao investigador que se presume colocar uma base histórica para enfrentar argumentos antropológicos, deveríamos endireitar um pouco o alvo, sobretudo na escolha das fontes principais.

Não concordo com a observação acerca da territorialidade dos reinos (SERRANo 2014: 33), como se a subdivisão fosse uma consequência da ocupação europeia. Há que ter em conta o mito de origem que a tradição oral bakongo fixou sobre a subdivisão das terras e apraz-me referir aquilo que no conhecido livro Kinkulu kya nsi eto a Kongo o investigador belga De Munck escreve:

«Kansi muna zaya fulu kina kyakala Mbanza Kongo ya ntete mpasi beni kadi mafunda ma mvu mavyokele va kati ye bakulu ka batusisa nkanda ko. Bana ye batekolo ba mfumu Na Kongo va banyeka, va babilama bamwangana, Bamenda tunga dyaka nsi zankaka. Bankaka, i Bavili ye BaKabinda Bamenda tunga ku ndambu za kalunga. Bavanga Kimfumu kya Loango; mbanz'au: Loango vo Bwali. Bankaka betunga kuna nsi a Kikongo, mbanz'au Kingwele, Bankaka batunga kimfumu kya Ngoyo: mbanza au mbanza Ngoyo: i kuna babokelwanga Ba-Kabinda» (DE MuncK 1956: 10-15).

Entendo assim que não podemos exagerar atribuindo sempre a causas externas que hipoteticamente interferiram no contexto sociopolítico cabinda, comprazendo as teorias de doutos africanistas 
como Jean-Loup Amselle, antes de considerar autores nossos angolanos como António Fonseca que, mesmo sem grandes pretensões, aclara sobre a organização social bakongo:

«Tradições recolhidas por nós na região do Tomboco pretendem que, paralelamente às guerras de conquista, alguns elementos da família de Ne Kongo, devido a descontentamento e outros problemas, emigraram do Kongo dia Ntotela para outras regiões; esta teria sido a situação que esteve na origem da deslocação de um grupo de Kikongos para a região que é hoje a província de Cabinda» (FonsECA 1985: 27).

Mas aquilo que deve permanecer no fundo de tudo isso, antes de se recorrer ao colono como causa de todos os males, é necessário começar por analisar os mitos de origem que são de cabal importância para um estudo sério que possa dizer-se antropológico acerca de uma etnia. Mesmo nos dias de hoje, os Bakongos continuam a transmitir uma preciosa tradição acerca do mongo a kayila, a partir do qual, por causa do grande incremento demográfico, foram distribuídas terras às linhagens.

Nesta conformidade, teria sido necessário referir-se aos estudos de Alfredo de Albuquerque Felner e de Hélio Esteves Felgas acerca da distribuição das linhagens bakongo, sem limitar a análise ao grande missionário espiritano, o senhor padre Martins. Na página 35, o nosso autor conclui que «existem poucas informações [...] que nos falem dos primeiros povos na margem direita do Zaire», provavelmente, em nosso modesto entender, porque se desconhecem as obras de Richard Edward Dennett e de Levin-Bonaventure Proyart. No entanto, é bom lembrar toda a viagem feita pelos precursores da Baptist Missionary Society (вмS) que, conjuntamente com o missionário Bentley, no interesse da Sociedade Geográfica de Londres, percorreram toda a costa do rio Zaire antes de virem a se estabelecer definitivamente em Mbanza Kongo, em meados de 180o. Dessa viagem, e de outras pesquisas que levaram a cabo estes pioneiros protestantes até aos Camarões, fala-se amplamente nos dois volumes de Jonhston acerca das viagens de Grenfell ao Congo. Portanto, a pesquisa não pode limitar-se somente ao grande artista holandês Dapper e ao ex-refém Andrew Battel, na elaboração sumária da história dos estudos das etnias em Cabinda.

Ao terminar o primeiro capítulo da sua obra, Carlos Serrano vê-se atolado num argumento bicudo: a questão da teologia cabinda, e 
resulta evidente que ao colocar Balandier (2014: 46) como referente do Nzambi bakongo é como meter juntos o diabo e a água benta. De facto, o autor acaba por criar uma organização social teológica onde Nzambi se encontra rodeado de bakisi ba nsi, nganga e outros tantos agentes do sagrado que, com a benção de MacGaffey, formam mesmo um grande e confuso panteão (2014: 50). Aos conhecedores da língua kikongo não foge a estranha etimologia de Nzambi a Mpungu definido como «o que se fez a si mesmo» (2014: 52). A este respeito a etnolinguística kikongo baseia-se na explicação de Van Wing, que Serrano de facto cita, mas ficando um tanto desnorteado quando tenta descrever os inúmeros seres que pupulam na cosmologia cabinda. Enfim, teria sido louvável se Serrano pudesse tentar pôr essa questão em ordem, visando iluminar os nossos leitores sobre este complexo mundo.

O terceiro capítulo oferece um conjunto de dados etnográficos contextualizados na antropologia política dos Cabinda. Falar do poder e do espaço poderia ser um corolário do sistema e da organização social dos Senhores da Terra e os Homens do Mar. O contexto que justifica a abordagem das linhagens como componente social não é a política, mas a organização socio-cultural e torna-se difícil falar do poder e do espaço sem antes explicar como a linhagem se organiza nos seus componentes. Achamos ser este o contexto mais oportuno, mas sendo Balandier quem dita as leis, tudo o que estiver consoante o seu dinamismo é justificado mesmo se isso puder dar lugar a uma certa confusão entre elementos tão diferentes (2014: 65-69) e colocados sem ter em conta o seu verdadeiro contexto. Entretanto, afigura-se-nos interessante a tradução explicativa fornecida pelo autor sobre a famosa «casa das tintas», a Nzo tchikumbi (2014: 70).

Na abertura do quarto capítulo, há um elemento que à partida nos impressiona: é o uso do termo «segmentário» de Pritchardiana memória, como atributo da organização da etnia bawoyo e, mais ainda, associado à perspectiva da contemporaneidade de Marc Augé (SERRANO 2014: 77). Sublinhamos que o termo «segmentário» refere-se a um conjunto acéfalo de pessoas que convivem sem formar corpo social nenhum. Por isso define-se como segmentário mas, sem dúvida nenhuma, não é este o caso dos Bawoyo que, ao invés, formam uma sociedade bem organizada. Se Edward Evans Evans-Pritchard aplica a segmentariedade aos Nuers nós poderíamos aplicá-la aos 
«Khoisan» do Kwando-Kuvango por viverem em núcleos familiares não linháticos mas, de facto, segmentários; portanto, não temos dúvidas, não é apropriado referir este termo para os Bawoyo, que não é uma etnia segmentária mas organizada, aliás está constituída em sobados e reinados fruto de privilégios de linhagens que se destacam pelo sangue real. Achei deveras interessante o relato de Tollenare acerca da rainha bawoyo conduzida como escrava nas fazendas de cana de açúcar brasileiras (2014: 83), pois, foi exactamente no ano passado que apareceu uma nobre afrobrasileira acompanhada por duas damas de companhia em Luanda a procura de paradeiros, com a única certeza de ser descendente real do rei do Kongo; mas, com muita pena, não sabia a sua linhagem (ngembo mayalalele).

Acho arriscado falar de propriedade colectiva nas sociedades segmentadas, pois são formadas por caçadores-colectores e raramente de pastores. Mas é lógico que, onde há propriedades, há também quem distribuiu as terras (mfumu a nsi), denotando assim a presença duma organização territorial que não tem nada que ver com a segmentariedade: a bela descrição da sociedade bawoyo feita na página 101 parece conter uma contradição de termos.

Os Senhores da Terra e os Homens do Mar, parece constituir uma apreciada novidade no contexto da antropologia brasileira, que contribui para escassez editorial do nosso mercado sobre argumentos especificamente etnográficos. Nesta mesma linha de pensamento, lembro que têm surgido outros investigadores que se têm desfrutado com a riqueza etnográfica dos Bakongo, nomeadamente dos residentes do Bairro Palanca e outros lugares de Luanda, como se aí se espelhassem todos os Bakongos de Angola (Pereira 2008). Enfim, apesar destas perigosas generalizações que abundam no ultramar brasileiro, a nossa atenção é mais uma vez despertada num argumento que constitui honra para todo o povo de Cabinda, e riqueza para a florescente etnografia angolana.

\section{Referências bibliográficas}

BALANDIER G. 1965, La vie quotidienne au royaume de Kongo du Xvième et au XVIIѐme siècle. Paris, Hachette.

1963, Sociologie actuelle de l'Afrique Noire. Paris, Presses Universitaires de France. 
De Munck J.

1956, Kinkulu kia Nsi eto a Kongo [Histoire de notre pays]. Tumba, Mission Catholique de Tumba.

DENNETT R. E.

1887, Seven years among the Fjort. Londres, Gilbert and Rivingston.

Evans-Pritchard E. E.

2012, I Nuer. Un'anarchia ordinata. Milano, Franco Angeli.

FonsECA A.

1985, Sobre os Kikongos de Angola. Luanda, União dos Escritores Angolanos; Lisboa, Edições 70.

JoHNSTON H.

1908, George Grenfell and the Congo, 2 vol. London, Hutchinson.

PEREIRA L. N. N.

2008, Os Bakongo de Angola. Etnicidade, religião e parentesco num bairro de Luanda. Rio de Janeiro, Livraria Contra Capa.

Proyart B. L.

1776, Histoire de Loango, Kakongo, et autres royaumes d'Afrique. Paris-Lyon, Berton-Crapart, Bruyset-Ponthus.

WING J. Van

1959, Etudes bakongo. Sociologie, Religion et Magie. Bruxelas, Desclée de Brouwer [«Museum Lessianum - Section Missiologique»; 39].

1941, «Bakongo Magic», Journal of the Royal Anthropological Institute of Great Britain and Ireland, vol. 71, n. ${ }^{\circ}$ 1-2, pp. 85-97.

\section{Bortolami Gabriele}

(cf. supra, pp. 267-268) 